\title{
ANÁLISE DE UMA EXPERIÊNCIA NA FORMAÇÃO INICIAL DE PROFESSORES COM O USO DA TV MULTIMÍDIA ${ }^{1}$
}

\section{ANALISYS OF AN EXPERIENCE ON THE INITIAL FORMATION OF TEACHERS USING THE MULTIMEDIA TV}

\author{
Bárbara Grace Tobaldini - GECIBIO/ Curso de Ciências Biológicas - UNIOESTE \\ (barbaragt@ibest.com.br) \\ Juliana Moreira Prudente de Oliveira - GECIBIO/ UNIOESTE e Mestranda do \\ Programa de Pós-Graduação em Educação para a Ciência e a Matemática - UEM \\ (julifari@yahoo.com.br) \\ Daniela Frigo Ferraz - GECIBIO/ Curso de Ciências Biológicas - UNIOESTE \\ (dfrigoferraz@gmail.com)
}

\begin{abstract}
Resumo: Com o intuito de contribuir para a formação inicial de alguns acadêmicos, quanto à utilização de um recurso tecnológico, a TV Multimídia, foi proposto um projeto de extensão que proporcionou aos envolvidos um primeiro contato com a realidade escolar e ao mesmo tempo testar o uso desse recurso. O objetivo foi investigar a postura de acadêmicos durante o desenvolvimento de um Módulo Didático (MD) sobre a temática de Educação Ambiental (EA) utilizando o recurso tecnológico: TV Multimídia. Para coleta de dados, utilizaram-se três instrumentos: um questionário, o MD produzido de EA e a vídeo-gravação da aplicação do MD por duas bolsistas. O resultado desta análise evidenciou que o uso do recurso tecnológico, na concepção dos acadêmicos, foi importante para motivar os alunos, criar uma interatividade com a turma, além de facilitar a contextualização dos conteúdos. Entretanto, o professor deve estar atento e preparado para ser o mediador de tais informações, pois o recurso em si, não é sinônimo de um processo de ensino eficaz.
\end{abstract}

Palavras-chave: ensino de ciências; articulação universidade e escolas; TV multimídia

\begin{abstract}
Aiming to contribute on the initial formation of some academics about the usage of a technological resource, the Multimedia TV, it was purposed an extension project which provided to those academics, a first contact to school reality and at the same time to probe the usage of such resort. The objective was to investigate the position of academy students during the development of a Didactic Module (DM) over the thematic Environmental Education (EE) taking hand of the mentioned technological resort. To collect the data, there were used three instruments: A questionnaire, the produced DM from EE and the video shooting of the DM's application by two scholarship students. The analysis' result highlighted that the usage of the technological resource, in the conception of the scholarship students, it was very important to motivate the school students, build up some interaction with the class, and even making easy the understanding of the contents. However, the teacher must be attentive and prepared to mediate such information, for the resource itself is not a synonym of an effective teaching process.
\end{abstract}

Keywords: science teaching, articulating school and university, multimedia TV.

\footnotetext{
${ }^{1}$ Apoio SETI/PR - Secretaria de Estado da Ciência, Tecnologia e Ensino Superior.
} 


\section{Introdução}

A educação constitui a base de toda a formação e organização humana. Os instrumentos utilizados durante todo este processo são de extrema importância para construção e reprodução de visão de mundo, além da formação de cidadãos efetivamente participativos e estimulados. Partindo-se deste ponto é visível a necessidade de adequações didáticas de ensino/aprendizagem que alcancem a tais expectativas, criando condições que permitam interconexões com o processo educacional e a evolução de recursos tecnológicos como meios para alcançar uma aprendizagem diferenciada e significativa (Finger et al., 2009).

Nessa direção, considera-se imprescindível a discussão de assuntos relacionados ao campo tecnológico nos cursos de formação inicial docente. Tendo em vista que é durante a formação inicial que os professores irão desenvolver as primeiras experiências didático-pedagógicas relacionadas ao processo de ensino-aprendizagem a discussão da importância do uso de recursos tecnológicos faz-se necessária para desenvolver uma postura que atenda as reais necessidades do atual contexto educativo. Ou seja, verificase uma crescente demanda por professores preparados para lidar com as diferentes tecnologias digitais que começam a fazer parte da realidade escolar.

Especificamente no contexto investigado no presente trabalho, as escolas públicas do estado do Paraná vêm equipando suas salas de aula com a TV Multimídia, também conhecida com TV Pendrive ou ainda 'Laranjinha'(Figura 1). Esta consiste em um aparelho televisor de 29' que conta com uma conexão USB, leitor de cartão de memória, entradas para DVD e VHS e está presente nas 22.000 salas de aula do estado do Paraná (Paraná, 2008). Esta conexão é utilizada com o dispositivo pendrive que é capaz de armazenar arquivos digitais, como: filmes, imagens e sons, além de comportar objetos de aprendizagem presentes no portal Dia-a-dia Educação do Estado do Paraná.

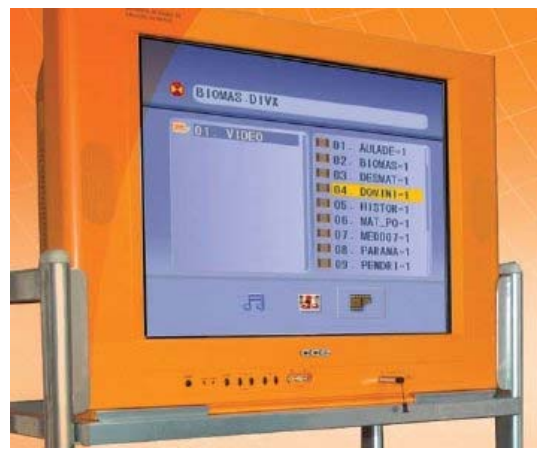

Figura 1- Imagem da TV Multimídia Fonte: http://www.profanderson.net/files/extensao_introducao.php

A vantagem deste dispositivo é a sua reutilização bem como sua capacidade em armazenar os arquivos. De acordo com o Portal Dia-a-Dia Educação (Paraná, 2009) encontrado no site esta integração da TV com o pendrive não é sinônimo de eficiência:

"A inserção do recurso tecnológico na escola não é garantia de uma transformação efetiva e qualitativa nas práticas pedagógicas, mas pode provocar profundas transformações na realidade social, desde que seu uso seja adequado com uma prática que propicie a construção de conhecimento e não a sua mera transmissão” (Paraná, p.1, 2009).

Assim é necessária uma formação docente no campo tecnológico, porém, como ressaltado anteriormente, não se pode esquecer que o uso deste recurso não irá resolver os problemas em sala de aula, bem como que sua inserção na educação pode propiciar o questionamento sobre a forma tradicional de ensino. 
Para refletir sobre essas questões, durante um projeto de extensão, com interface na pesquisa, denominado "Articulação entre formação inicial na licenciatura em ciências biológicas e a comunidade escolar: trilhando novos caminhos” oportunizou-se o uso de recursos audiovisuais diversificados com o auxílio da TV Multimídia para o planejamento e implementação das atividades propostas.

No trabalho aqui apresentado investiga-se a postura de estudantes em formação inicial durante o desenvolvimento de um Módulo Didático (MD) sobre a temática de Educação Ambiental (EA), utilizando o recurso tecnológico: TV Multimídia. Com isso, pretende-se apontar quais foram as contribuições que o recurso trouxe para a prática pedagógica dos acadêmicos envolvidos bem como sua importância na mediação do conhecimento científico durante a formação inicial de professores.

\section{Fundamentação Teórica}

De acordo com Andrade (2000), grande parte dos professores utiliza o recurso das linguagens audiovisuais em suas aulas, no entanto a maioria não possui conhecimento acerca da sua utilização, pois as licenciaturas, não incluem no seu currículo o estudo dos recursos audiovisuais.

“... escolas recebem computadores e professores não sabem o que fazer. Portanto, a compreensão da natureza e do funcionamento das tecnologias, nomeadamente, tecnologias de informação e comunicação, deve ser estendida aos professores” (Melo et al. , 2008).

Esse fato também se aplica para os demais recursos tecnológicos que têm tomado espaço nas escolas de educação básica, como a TV Multimídia, por exemplo, que pode ser considerada como uma Tecnologia de Informação e Comunicação (TIC). Segundo Costa (2003), a utilização das TIC na aprendizagem não está recebendo uma atenção especial pelas universidades que promovem a formação inicial, por mais que seu reconhecimento venha sendo gradual, os resultados estão se mostrando pouco animadores, o que levam muitos a concluir que a quantidade e a qualidade das informações que os futuros professores recebem, ainda são insuficientes dificultando que seus alunos promovam situações de aprendizagem motivadoras, instigantes e mais próximas da realidade.

Para Aguiar (2003) os professores podem adotar duas atitudes: a primeira é ver os meios de comunicação como uma alternativa para suprir as necessidades escolares e outra é acreditar que estes meios podem dominar suas aulas e por isso devem ser ignorados no contexto escolar. No entanto, Loizos (2002, p. 108) afirma que o “... o visual e a mídia desempenham papéis importantes na vida social, política e econômica. Eles não podem ser ignorados”. Mas como agir sabendo que a mídia tem influenciado nas mais diversas áreas, através das suas representações e significações que estão atingindo diretamente o cotidiano das pessoas. Como então usar este meio, que tanto atrai as crianças, os adolescentes e jovens na sala de aula?

Do ponto de vista educacional, Bruzzo (1999) aponta alguns aspectos que devem ser pensados sobre os recursos audiovisuais: os filmes, programas televisivos e videogame ocupam um tempo considerado dos alunos enquanto não estão na escola, passando mais tempo nestas atividades do que se dedicando aos estudos. Eles também se informam e constituem suas idéias de mundo de acordo com aquilo que visualizam. Outro ponto é que os vídeos são apresentados de forma intensa e rápida, tornando o mundo naquele instante mais próximo, do que seria tão difícil e distante de visualizar. Se os alunos estão inseridos intensivamente neste meio, porque não utilizá-lo em sala de aula? Assim os professores podem utilizar destes recursos como um apoio para suas aulas, relacionando o conteúdo com as imagens e vídeos. 
Para Móran (1995), o vídeo explora o ver, visualizar, o ter diante de nós as situações, as pessoas, os cenários, as cores, as relações espaciais. O ver está na maior parte das vezes, apoiando o falar, o narrar, o contar histórias. A fala aproxima os vídeos do cotidiano, de como as pessoas se comunicam. Os diálogos expressam a fala coloquial, enquanto o narrador costura as cenas, as outras falas, dentro da norma culta, orientando a significação do conjunto. O vídeo tem sua força por nos atingir em todos os sentidos e de todas as maneiras. O jovem lê o que pode visualizar, precisa ver para compreender. Assim para se trabalhar com os vídeos se faz necessário o uso de roteiros, para que a atenção dos alunos não se dissipe e nem que seja usado como "vídeo tapaburaco”, "vídeo enrolação”, "vídeo deslumbramento”, "vídeo perfeição”, ou ainda só vídeo.

De acordo com Mandarino(2002) citado por Pereira (2009, p.40):

"quando analisamos um produto audiovisual, precisamos ter em mente o que pretendemos com o seu uso em sala de aula, quais são nossos objetivos e até que ponto um programa ou filme consegue atendê-lo, apesar de peculiaridades ou imperfeições que podemos superar com um bom planejamento de utilização".

Além disso, este planejamento deve contar com o uso de analogias com outros dados que já foram ou que será abordado em sala de aula, motivação do aluno por um conteúdo já visto, ou o instigar para a próxima etapa do estudo, deve contar também com uma complementação baseada em conceitos científicos buscando uma aproximação do aluno, além de proporcionar ao aluno uma visão critica do mundo e das mais diferentes formas de conhecimento (Pereira, 2005).

Verifica-se, portanto, a importância da utilização de recursos audiovisuais que podem ser utilizados com o intuito de aproximar às técnicas mais convencionais na educação proporcionando um ensino mais rico, produtivo e criativo.

Sabendo-se da importância de proporcionar uma educação com um enfoque crítico e criativo o uso dos recursos tecnológicos, sempre mediados pelo sujeito professor, podem proporcionar a problematização dos dados que nos chegam direta e indiretamente recontextualizando-os numa perspectiva de conjunto, totalizante, coerente, um novo texto, uma nova síntese criadora. Essa síntese integra os dados tanto conceituais quanto sensíveis, tanto da realidade quanto da ficção, do presente e do passado, do político, econômico e cultural (Móran, 2007).

\section{O contexto do projeto e seus recortes no presente trabalho}

O projeto "Articulação entre formação inicial na licenciatura em Ciências Biológicas e a comunidade escolar: Trilhando novos caminhos" foi aprovado no ano de 2007 e contou com o financiamento do Programa Universidade Sem Fronteiras, desenvolvido pela Secretaria de Estado da Ciência e Tecnologia e Ensino Superior (SETI) do Paraná. O programa subdividia-se em cinco sub-programas, dentre eles o “Apoio às licenciaturas”, no qual o referido projeto se inseriu.

As atividades propostas foram desenvolvidas em duas etapas: a primeira de Outubro/2007 a Setembro/2008 e a segunda de Outubro/2008 a Outubro de 2009. Na primeira etapa foram trabalhadas três temáticas: Afetividade/ Auto-estima, Sexualidade e Higiene/ Nutrição e na segunda desenvolveu-se outras duas temáticas: Educação Ambiental e Drogas.

Essas temáticas foram selecionadas pelas quatro escolas públicas participantes por se tratarem de assuntos pertinentes a realidade escolar, que faziam parte de suas preocupações; sendo que as atividades propostas pelo projeto objetivaram aprofundar as temáticas. Nesse sentido, foram propostos durante o desenvolvimento do projeto a implementação do MD baseado em uma proposta metodológica com enfoque na 
problematização, mais especificamente na metodologia dos momentos pedagógicos propostos por Delizoicov; Angotti (1994). Esses MD's envolviam uma ou mais temáticas, além de um conjunto de atividades e recursos didáticos, que foram planejados de acordo com os pressupostos teórico-metodológicos citados anteriormente.

De acordo com os autores, a problematização dos conteúdos pode ser feita mediante o diálogo entre alunos e professores durante três momentos pedagógicos principais, que são: Problematização Inicial (PI): momento em que o conhecimento científico é relacionado com situações do cotidiano dos alunos para que busquem as possíveis interpretações sobre os fenômenos; Organização do Conhecimento (OC): momento em que os fenômenos são estudados de forma sistematizada incorporando o conhecimento científico e a Aplicação do Conhecimento (AC): momento onde ocorre a análise dos questionamentos iniciais e dos realizados pelos alunos, relacionando o conhecimento incorporado e a explicação dada pelo aluno.

Analisa-se aqui o desenvolvimento do segundo momento pedagógico, a OC, do MD sobre a temática de EA. A escolha do tema pelas escolas ocorreu devido à importância que a temática apresenta por se tratar de um assunto relacionado à comunidade escolar em questão e ser um assunto bastante difundido na mídia e nos diferentes meios de comunicação. No entanto, poucas atitudes concretas são adotadas pelas pessoas, por isso torna-se necessário discutir tal temática durante as aulas de ciências de forma a sensibilizar os alunos e de propiciar que estes consigam elaborar um pensamento crítico a respeito das ações/atitudes com o meio ambiente.

No MD da temática de EA (Vieira; Oliveira, 2009) a TV Multimídia, esteve presente nos três momentos pedagógicos, sendo utilizado na PI, durante a atividade de sensibilização com a reprodução de áudio da Música 'Aquarela', com o objetivo de estimular a imaginação dos alunos para as próximas atividades que viriam realizar. Na OC, o recurso foi utilizado para apresentar alguns slides que direcionavam a aula para um debate, a respeito do meio ambiente e das interações do homem com os impactos ambientais. E ainda, foi possível apresentar aos alunos um vídeo sobre o ciclo da água, relacionando-o com os fatores abióticos presentes na natureza.

No terceiro momento, AC, o recurso foi utilizado para a apresentação do vídeo “Tá Limpo”, que tinha o intuito de recapitular as teorias e debates realizados em sala de aula, além de estimular os alunos a pensarem em atitudes que possam ajudar na preservação do meio ambiente.

\section{Aspectos metodológicos da pesquisa}

A pesquisa se configurou com a análise de três instrumentos: um questionário, o MD da temática de EA e a vídeo gravação da implementação do mesmo MD por duas acadêmicas bolsistas.

O questionário foi aplicado aos cinco bolsistas participantes da segunda etapa do projeto, citado anteriormente. As questões eram abertas e estavam relacionadas à atuação em sala de aula, ao uso de recursos tecnológicos como a TV multimídia, especificamente às limitações e sucessos e como foi realizado o planejamento para utilização dos vídeos e imagens. Deste instrumento, utilizou-se na análise do trabalho aqui apresentado apenas o questionário respondido por duas bolsistas cuja implementação do MD de EA foi vídeo gravado.

O MD desenvolvido permitiu verificar que durante a OC, a TV Multimídia foi utilizada para o desenvolvimento das atividades, tanto para a exibição de imagens como de vídeos. Com isso, realizou-se a análise deste momento mediante a análise da vídeo gravação das duas bolsistas. 
As bolsistas foram identificadas por B1 e B2, e os alunos participantes de suas aulas, por A1 à A10 e A1' à A2', respectivamente. Além de algumas simbologias que foram utilizadas durante a transcrição das falas, como: (...) e (xxx) as quais recebem o seguinte significado: pausa curta e pausa longa, respectivamente.

Portanto, este estudo caracteriza-se como uma análise qualitativa que é definida por utilizar o material obtido durante a pesquisa, como relatos das observações e das demais informações disponíveis (Ludke; André, 1986).

De acordo com os autores, esta análise implica em organizar o material, de forma a identificar as tendências e padrões relevantes. Os quais serão novamente avaliados, buscando relações e inferências em um maior nível de abstração. Com isso estaremos incorporando nas discussões deste trabalho as falas pertinentes à aplicação das atividades durante o desenvolvimento da OC, as respostas fornecidas nos questionários e a análise escrita do MD, deste modo o uso da TV Multimídia será analisado nas diferentes situações apresentadas.

\section{Resultados e Discussões}

A primeira pergunta proposta questionava se a TV Multimídia teve alguma importância ao ser utilizada em sala de aula. As acadêmicas bolsistas apontaram que este material motivou o interesse dos alunos pelo assunto, permitindo que os conteúdos fossem melhor trabalhados e de maneira dinâmica. Como pode ser verificado nas falas seguintes:

B1: "Sim, teve muita importância. Com o recurso da TV pendrive, das imagens e dos vídeos os alunos se interessavam bem mais pelo assunto abordado, prestavam mais atenção a fala e aprendiam o conteúdo de várias outras formas. Por exemplo: visualizando as imagens, os vídeos, ouvindo as músicas, vendo fotos colocadas entre os slides. E assim esses recursos didáticos favorecem muito mais os professores e os alunos na sua aprendizagem".

B2: “A TV pen-drive é uma tecnologia bastante favorável para nós educadores, ela veio com o objetivo de facilitar a passagem de vídeos, imagens, slides aos alunos..." "O uso de vídeos e imagens se mostrou muito eficiente, pois permite um melhor desenvolvimento de conceitos de maneira descontraída".

Nas falas acima se pode destacar que para as acadêmicas bolsistas a TV Multimídia foi um instrumento essencial à sua prática por possibilitar melhor visualização quanto aos conteúdos o que motivou os alunos a prestarem mais atenção nas suas explicações durante a aula. Corroborando com isso Martinho; Pombo (2009), afirmam que o uso de vídeos e imagens influencia de forma positiva a aprendizagem dos alunos, já que os mesmos prestam mais atenção e apresentam mais entusiasmo durante as aulas.

A bolsista B2, mencionou ainda que o uso deste equipamento se faz muito útil por facilitar o desenvolvimento dos diferentes conceitos, mediante a visualização do conteúdo. A partir disso, pode-se encontrar em trabalhos que analisaram recursos tecnológicos semelhantes (Gomes-Maluf; Souza, 2008; Machado, 2008; Machado; Nardi, 2006.) que o uso destes, também proporcionou discutir os conceitos trabalhados. Machado; Nardi (2006) afirmam que os conceitos podem ser associados com imagens, animações, filmes e sons.

A partir das evidências presentes no questionário, realizou-se a análise da vídeogravação durante a OC das duas bolsistas. Neste momento, pode-se perceber que a bolsista B1 iniciou a apresentação dos slides com um diálogo, o que contribuiu para o 
estabelecimento de uma interatividade com a turma, como pode ser observado nas falas que seguem:

B1: "O que vocês entendem por ecossistema? Ecossistema é igual a gente falou de meio ambiente é tudo tá, é a gente, é os animais, é as plantas é o ambiente que a gente vive, aqui onde a gente está agora, as árvores lá fora. Então gente no ecossistema a gente tem dois tipos de fatores abióticos e os bióticos, quem sabe o que que é seres abióticos?

A1: "Quem não tem vida!"

B1: "Isso mesmo, quem não tem vida, me dá um exemplo:

A1: "Pedra"

B1: "Olha vocês podem ver ali o rio, o solo, o calor, a água tudo o que não tem vida.

A2: "E biótico é os seres que tem vida.

B1: "Isso mesmo! É biótico.

A3: "Animais"

A4: "As árvores

A2: "O gavião"

B1: O gavião, o homem são seres bióticos tá bom? E agora eu vou passar um vídeo da água para vocês, é bem legal, depois a gente vai discutir um pouquinho sobre a água.

A bolsista B2 por sua vez, também iniciou do mesmo modo:

B2: "Gente, pra gente começar a falar sobre meio ambiente é interessante a gente falar sobre ecossistema. O ecossistema... quem sabe aqui o que é eco?

A1': "Ecologia?"

A2: "Ambientalista?"

B2: "Eco, tem os eco certinho, ah ela é um eco chato! ah, eu sou um eco chato!

B2: "Só falam que tem que cuidar do Meio Ambiente! Que não pode jogar lixo no chão. O ecossistema gente... eco quer dizer casa né, e... os constituintes do ecossistema que constitui a nossa casa? A nossa casa é o mundo que a gente vive, o planeta terra ou a nossa casa, a nossa cidade... Essa é a nossa casa né? Pra gente falar de ecossistema, a gente tem que saber que tem fator biótico e abiótico. Quem sabe me dizer o que é bio?

A2': "Vida!"

B2: "Vida! Muito bem! Os fatores bióticos são fatores assim que influenciam e que tenha vida envolvida, igual a formiga é um fator biótico, tem a onça lá é um fator biótico, nós somos um fator biótico, onde a vida ta interagindo com os fatores abióticos. E o que são fatores abióticos? Quem sabe me falar?

Os alunos não respondem (...).

B2: "Os fatores abióticos que dizem que não tem vida né? O que não tem vida? É a água, o clima né? Que não tem vida envolvida? A rocha né. Então assim o ecossistema é um convívio entre os fatores bióticos: nós, as plantas e os outros animais: a onça, a formiga, a barata com os fatores abióticos que seria o clima né, a temperatura, o rio, a gente precisa da água né pra ta sobrevivendo no solo, né então esses são os fatores abióticos tudo isso constitui o ecossistema pra manter o equilíbrio. Aqui tem um vídeo bem legal sobre a água que eu vou mostrar para vocês. Vocês gostam de vídeos?”.

Todos: "Sim"

Pode-se então inferir que neste momento a aula foi condizente com as respostas apresentadas nos questionários, ou seja, o uso dos slides por meio da TV Multimídia, entre outros fatores, favoreceu uma maior interação com a turma. Para Netto et al. (2009) a interatividade é a abertura para uma maior comunicação, troca e participação. E para que isso ocorra é necessário que haja bom trânsito entre professor-aluno, retroalimentação sistemática, estímulo à participação, estilo de comunicação do professor, conhecimento e utilização das ferramentas de comunicação.

Para dar continuidade ao trabalho, as bolsistas enfocaram o fator biótico "água" para passar um vídeo aos alunos sobre o ciclo da água, bem como a forma de tratamento 
realizada nas estações de água. Após a visualização do vídeo, as bolsistas procederam com alguns questionamentos para discutir o vídeo, como pode ser verificado a seguir:

B1: "Aquelas gotinhas eram o quê?"

A1: "Eram água"

B1: "E tavam explicando o quê?

A1: "O ciclo da água"

B1: "A mulher que tava lá com a mangueira ligada, a mãe de vocês faz isso também?"

A2: "Não, não faz isso porque gasta muita água".

B1: "E quando vocês estão escovando os dentes, vocês deixam a torneira aberta?"

A3: "Abre e fecha".

B1: "Vocês tomam banho de quanto tempo?"

A3: "Dez minutos".

A6: "Prof. Minha prima fica uma hora tomando banho" (...)

B1: "A gente pode economizar água como, então?"

A6: "Usando a vassoura".

A7: "Deixando a mangueira desligada".

A8: "Tomando banho rápido".

A10: "Deixando a torneira desligada na hora de escovar os dentes".

Neste trecho verifica-se que a acadêmica explorou o vídeo e os slides a partir de questões ambientais, como a economia de água, para contextualizar com o dia-a-dia dos alunos, além de despertar a curiosidade e motivação dos mesmos, sendo que respondiam quando eram indagados, participando ativamente da discussão do conteúdo. Móran (1995) aponta que os vídeos podem ser utilizados tanto para despertar a curiosidade e motivação dos alunos, quanto para trabalhar um assunto de forma direta ou indireta, como pode ser observado no trecho anterior. Quanto ao incentivo à participação dos alunos, Santos (2002) destaca que a maneira de relacionar-se consigo próprio e com o outro, pode proporcionar uma participação do aluno na construção de seu aprendizado, o que lhe oportuniza melhores condições de relacionar-se com o mundo.

A bolsista B2, para prosseguir com a atividade, optou pela exposição do conteúdo, em que relacionou as informações do vídeo com questões ambientais, como a poluição das águas, a partir de uma situação real, conforme demonstrado abaixo:

B2: "Essas algas proliferam e vão se espalhar, então elas vão captando tudo, elas vão se espalhar em todo o rio Tietê e daí debaixo as plantas não vão permitir que a luz do sol passe na água e os animais lá em baixo precisam da luz do sol, tem plantas, algas lá em baixo que precisam dessa luz para fazer fotossíntese. A gente diz se tem água tem vida então. Mas o rio vai morrer, vai se perdendo toda a biodiversidade que ele tinha né. Que tipo de bicho tem no rio de água doce? Tem peixe, as algas, os microscrustáceos, então a gente vai perdendo toda essa diversidade que tinha ali.

É importante ressaltar, aqui a contextualização que as acadêmicas fazem com situações próximas aos alunos, pois a escola, o ensino e a aprendizagem só têm sentido para o aluno quanto utiliza elementos de sua realidade para educá-lo, quando a vida escolar e a vida do aluno estão relacionadas, ou seja, quando a educação é a própria vida (Santos, 2002).

Sem diminuir a importância que essas relações e discussões tiveram para a aula, notou-se que quando as bolsistas passaram da explicação dos slides para a visualização do vídeo e ao retornaram deste para os slides, em nenhum momento houve contextualização do material no todo, mesmo existindo uma relação entre si. Ou seja, começaram a mostrar o vídeo sem relacioná-lo como sendo uma das explicações sobre um dos constituintes abióticos que estavam explicando anteriormente e, ao retornarem para os slides seguintes (Figura 2), tanto no MD escrito, como na vídeo-gravação, não 
houve uma relação entre as informações, o que pode ser verificado na seqüência dada para a aula:

B1: "Então tá gente: espécie, população e comunidade o que vocês conhecem disso?

A1: "População é o conjunto de todos os bichos iguais e espécie é um bicho diferente do outro".

Ou ainda,

B2: "o que, que é espécie? O que você acha que é uma espécie? Você acha que espécie é onça, leão, gato tudo junto é uma espécie?”

A1: "Não. Tem espécie de borboleta, tem espécie de cachorro".

B2: "A gente é uma espécie. E população o que vocês acham que é?"

A1: "Várias espécies".

\section{Espécie, população e comunidade}
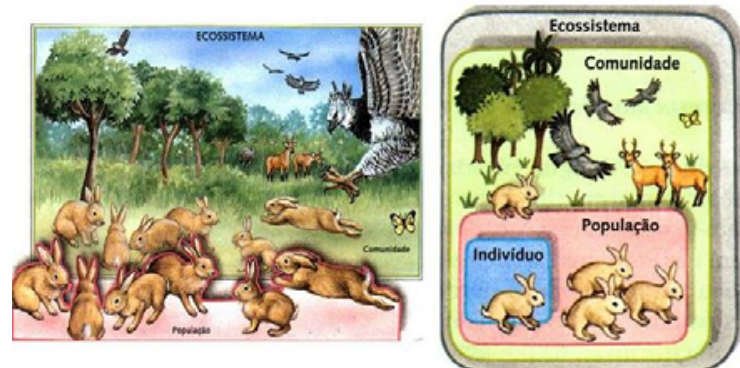

Figura 02 - Imagem utilizada após a visualização do vídeo sobre o ciclo da água.

No entanto, ao analisar o questionário, das bolsistas sobre os possíveis limites e possibilidades em utilizar dos recursos tecnológicos, encontramos a fala de B2, algo muito interessante e ao mesmo tempo contraditório a sua prática, já que esta indicou que ao utilizar dos recursos tecnológicos se faz necessário que o professor fique atento ao desenvolvimento de sua prática.

B2: "O uso de recursos didáticos, hoje parece ser muito necessário, é preciso trabalhar de maneira diferente, convidando aluno a receber o conhecimento de forma espontânea... mas ao mesmo tempo que é muito útil deve ser utilizado de maneira consciente e saber conduzir a dinâmica, pois o resultado vai depender de como o professor a abordou..."

Assim, é preciso selecionar com muito cuidado e atenção o material para que o aluno não interprete de maneira distorcida e diferente aquilo que é apresentado pelo professor (Silva, et al., 2006), já que o uso destes equipamentos não garante uma aprendizagem significativa por si só, e que segundo Sanmartí (2002) o professor continua sendo a peça chave das atividades em sala de aula, pois dependendo da forma como este planejou suas ações irá direcionar tanto para a forma de ensino mecanicista e de reprodução como também para processos integrados que promovam uma atividade escolar interessante, sendo que o ideal é que o professor procure a promoção do diálogo e do contraste entre idéias e fatos, e da regulamentação das formas de ver e pensar. No caso da acadêmica B2, sua fala demonstra uma visão ainda bastante passiva do processo de ensino-aprendizagem, ao afirmar que o aluno pode 'receber o conhecimento'.

\section{Considerações Finais}

Esta análise apontou que a TV Multimídia enquanto um recurso tecnológico pode ser eficiente, servindo como um recurso auxiliar do professor no ensino de ciências, possibilitando o uso de vídeos, imagens, músicas, além de propiciar a motivação, interatividade e contextualização do conteúdo, fatores estes que podem colaborar no processo de ensino. 
Entretanto, utilizar o material não é sinônimo de aprendizagem, é preciso que o professor tenha uma estratégia metodológica, um objetivo claro, e um planejamento para o recurso, de forma que este não seja utilizado de maneira aleatória e o principal, que o professor seja o mediador entre as concepções dos alunos, as idéias propostas pelo material e o conteúdo científico.

Por fim, considera-se importante a experiência obtida pelas acadêmicas durante sua formação inicial com o uso da TV Multimídia, já que é um recurso com o qual irão se deparar durante sua prática pedagógica ao ingressarem nas escolas, sendo importante haver a troca do saber teórico-prático para que seus primeiros saberes-fazeres docentes possam se consolidar ao longo do curso e posteriormente na sua prática profissional.

\section{Referências}

AGUIAR, M.M. Leitura critica dos meios de comunicação de massa. In: LEITE, S.L. (Org.). Tecnologia educacional: descubra suas possibilidades na sala de aula. Petrópolis: Vozes, 2003. p.105-119.

ANDRADE, E.C.P. de. O professor de biologia e o cinema: possibilidades de discussão com o filme Blade Runner. Coletânea do VII Encontro Perspectivas do Ensino de Biologia. São Paulo, 2000.

BRUZZO, C. Filmes e escola: isto combina. Ciência \& Ensino, Campinas. n.6, p. 0306, 1999.

COSTA, F.A. Ensinar e aprender com tecnologias na formação inicial de professores. $2003 . \quad$ Disponível em: <www2.fpce.ul.pt/pessoal/ulfpcost/doc/CostaF(2003)FInicial.pdf> Acesso em: 05 jan. 2009.

DELIZOICOV, D.; ANGOTTI, J.A.P. Metodologia do ensino de ciências. São Paulo: Cortez, 1994. 208p.

FINGER, J.E.; SILVEIRA, J.S.; PINHEIRO, S.G. Recursos tecnológicos como estratégias de aprendizagem no ensino de ciências e biologia. Webartigos.com, Disponível em: <http://www.webartigos.com/articles/17705/1/pagina1.html> Acesso em: 20 maio 2010.

GOMES-MALUF, M.C.; SOUZA, A.R. A ficção científica e o ensino de ciências: o imaginário como formador do real e do racional. Ciência \& Educação, v.14, n.2, p.271-282, 2008.

LOIZOS, P. Vídeo, filme e fotografias como documento de pesquisa. In: BAUER, M.W.; GASKelL, G. (Org.). Pesquisa qualitativa com texto, imagem e som. Petrópolis: Vozes, 2002. p.137-155

LÜDKE, M.; ANDRÉ, M.E.D.A. Pesquisa em educação: abordagens qualitativas. São Paulo: EPU, 1986. 100p.

MACHADO, C.A. Filmes de ficção científica como mediadores de conceitos relativos ao meio ambiente. Ciência \& Educação, v.14, n.2, p.283-294, 2008.

MACHADO, D.I.; NARDI, R. Construção de conceitos de física moderna e sobre a natureza da ciência com suporte de hipermídia. Revista Brasileira de Ensino de Física, v.28, n.4, p. 473-485, 2006.

MARTINHO, T.; POMBO, L. Potencialidades das TC no ensino das Ciências Naturais - um estudo de caso. Revista Electrónica de Enseñanza de las Ciencias. v.8 n.2, p.527-538, 2009.

MELO, J.A.P; SILVA, R.M.G; FORSTER, M.M.S. Investigando sobre as concepções e a compreensão das tecnologias na educação. Revista E-Curriculum, São Paulo, v.4, n. 1, p.1-13, 2008. 
MÓRAN, J. M. O vídeo na sala de aula. Comunicação \& Educação, São Paulo. n.2, p.27-35, 1995.

MÓRAN, J. M. Desafios na comunicação pessoal. 3.ed. São Paulo: Paulinas, 2007. 248p.

NETTO, C.; FARIA, E.T.; RIOS, M. Fatores que Interferem na Interatividade em Ambientes Virtuais de Aprendizagem: um estudo de caso em cursos de Pós-Graduação a Distância. Renote - Revista Novas Tecnologias na Educação. UFRGS, v. 7, n. 3, p. 1-12, 2009.

PARANÁ. TV Multimídia: pesquisando e gravando conteúdos no pen drive/ Secretaria de Estado da Educação. Superintendência da Educação. Diretoria de Tecnologias Educacionais. Curitiba : SEED/ PR, 2008.

PARANÁ, Portal dia-a-dia Educação. Objetos de Aprendizagem. Disponível em: $<\underline{\text { http://www.diaadia.pr.gov.br/tvpendrive/modules/conteudo/conteudo.php?conteudo=2 }}$ >. Acesso em: 03 jan. 2009.

PEREIRA, P. O. Utilização de filmes no ensino de ciências: "vida de inseto" como exemplo. In: JUSTINA, L.A.D.; FERRAZ, D.F. (Org.). Conhecimentos biológicos e ensino de ciências e biologia. Cascavel: Edunioeste, 2009. p.37-53.

SANMARTÍ, N. Didáctica de las ciencias em la educación secundaria obligatoria. Madrid: Sintesis, 2002. 382p.

SANTOS, J.C. A participação ativa e efetiva do aluno no processo de ensinoaprendizagem como condição fundamental para a construção do conhecimento. Porto Alegre: UFRGS, 2002. 163p. Dissertação de Mestrado.

SILVA, H.C.; ZIMMERMANN, E.; CARNEIRO, M.H.S.; GASTAL, M.H.; CASSIANO, W.S. Cautela ao usar imagens na aula de ciências. Ciência \& Educação, v. 12, n. 2, p.219-233, 2006.

VIEIRA, L.P.; OLIVEIRA, A.L.; Módulo Didático de Educação Ambiental. In: Módulos didáticos para o ensino de ciências e biologia: uma abordagem temática (org.) FERRAZ, D.F.; OLIVEIRA, J.M.P.; JUSTINA, L.A.D. Cascavel: Edunioeste, 2009. 1 CDROM. 